\title{
PCDD/Fs profile in ambient air of different types factories and human health risk assessment in Suzhou of Jiangsu province ,China
}

\author{
Jie Sun ${ }^{\mathrm{a}}$, Jinshun Tang ${ }^{\mathrm{a}}$, Zhihai Chen ${ }^{\mathrm{a}^{*}}$, Jihua Nie ${ }^{\mathrm{b}}$, Shuyu Zhang ${ }^{\mathrm{b}}$, Jiafu Li ${ }^{\mathrm{a}}$

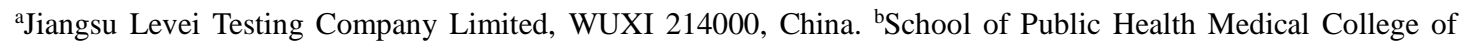 \\ Soochow university, SUZHOU 215123, China.
}

Tel: +86-510-85529981; Fax: +86-510-85529981.

Email addresses: tidechen@163.com (Zhihai-Chen)

\begin{abstract}
The objective of this study was to assess the potential health risks of polychlorinated dibenzo-p-dioxins and dibenzofurans (PCDD/Fs) in ambient air of different factories. In this study, fifty-five locations were selected and represented eleven type factories, including municipal solid waste incineration factory (MSWI), hazardous solid waste incineration factory (HSWI), sewage sludge treatment factory (SST), medical waste incineration factory (MWI), electronic factory (EF), pharmaceutical factory in large infusion (PILI), oral medication class factory (OMC), inorganic chemical factory (IC), organic chemical factory (OC), paper mills factory (PM) and mechanical factory (MF). We found that toxic equivalent concentration of $\mathrm{PCDD} / \mathrm{Fs}$ (TEQ) ranged from $0.236 \pm 0.198$ to $0.48 \pm 0.442 \mathrm{pg} \mathrm{I}-\mathrm{TEQ} / \mathrm{Nm}^{3}$ in $11 \mathrm{kinds}$ of factories, and average value of TEQs in 11 factories were lower than atmospheric PCDD/F standard (0.6 pg I-TEQ/m3) announced in Japan, and the mean values of TEQ in ambient air of factories were in the decreasing order of MWI $>$ MSWI $>$ PILI $>$ MF $>$ OC $>$ SST $>$ HSWI $>$ $\mathrm{OMC}>\mathrm{PM}>\mathrm{EF}>\mathrm{IC}$. In addition, lifetime average daily doses (LADDs) and their resultant excess cancer risks (ECRs) for workers in those factories were calculated. The results suggested that potential health risk might be occurred in those ambient air.
\end{abstract}

Key words: PCDD/Fs; Ambient air; Health risk assessment; Different factories; Excess cancer risks 


\section{Introduction}

Ambient air, one of the most important component of the environment, is being contaminated by polychlorinated dibenzo-p-dioxins and dibenzofurans ( $\mathrm{PCDD} / \mathrm{Fs})$, because of their long persistence (Ortuno et al., 2015), and their toxicity, semi-volatility, bio-accumulation in environment (Wang et al., 2016). The persistent organic chemicals (POPs) are often released from all kinds of factories (Rovira et al., 2014), including municipal solid waste incineration factory (MSWI), hazardous solid waste incineration factory (HSWI), sewage sludge treatment factory (SST), medical waste incineration factory (MWI), electronic factory (EF), pharmaceutical factory in large infusion (PILI), oral medication class factory (OMC), inorganic chemical factory (IC), organic chemical factory (OC), paper mills factory (PM) and mechanical factory (MF). Incineration, thermal processes and production process in those factories might produce numerous PCDD/Fs(Chen et al., 2014), those unintentional by-products via ambient air pose a health risk for people (Wegiel et al., 2014). The related reports have been described everywhere (Fu et al., 2015; Squadrone et al., 2016; Vallejo et al., 2015b), especially for local residents and workers in those factories (Liu et al., 2015; Rovira et al., 2014; Shi et al., 2008). In China, the air quality is becoming worse and worse due to the recent dramatic industrialization and urbanization activities to meet up the demands of increasing population (Zhang et al., 2014). Some researches showed that $1-5 \%$ of the mass of dioxins present in human body through inhaled air and $0.5-2 \%$ through skin (Wegiel et al., 2014). The researches about PCDD/Fs in ambient air were limited in East China and more studies were focused on the Shanghai City, which was the largest city in China.

In addition, PCDD/Fs were exposed to the human body could via many methods, it might potentially deep into the lungs and pose a health risk (Chi et al., 2013). However, most of these investigations have been focused on ambient air in the vicinity of the MSWI, HSWI and EW (Meng et al., 2016; Wegiel et al., 2014), evaluating the PCDD/Fs levels near those emission sources, and their impact on the environment. But there was few reports on ambient air in different 
factories. The objective of this study is to analyze the concentrations of PCDD/Fs in ambient air of different factories from an southern area of China and to assess the carcinogenic risk of PCDD/Fs, and the knowledge of air concentrations of those factories is important both for regulatory treaties and people health risk assessment.

\section{Materials and methods}

\subsection{Sampling}

In present study, Suzhou was located in southern China and with an area of $8488.42 \mathrm{~km}^{2}$ and with a population of 653,8400 . The ambient air samples were collected during August-October in 2015 from eleven factories in this city, including MSWI, HSWI, SST, MWI,EF, PILI, OMC, IC, OC, PM and MF. Polyurethane foam (PUF)(Rovira et al., 2014) disk samples were deployed at 5 sampling points in each factories , and distributing in industrial park of Suzhou(A), industrial park of Xiangcheng (B), industrial park of Wujiang (C), industrial park of Kunshan(D) and industrial park of Taicang(sites in fig.1), there were 55 sampling points in eleven factories.

According to preovious research (Zhang et al., 2014), the time of sampling were 7 days in each factories to ensure data reliability. The environmental temperature was controlled during each sampling period. Before sampling, the filter was baked at $450^{\circ} \mathrm{Cfor} 12 \mathrm{~h}$, and the PUF were pre-cleaned with methylene chloride in a soxhlet apparatus for $24 \mathrm{~h}$ (Liu et al., 2015).

Fig.1 Map of the studied area in this study (MSWI: municipal solid waste incineration factory; HSWI: hazardous solid waste incineration factory;SSI: sewage sludge treatment factory; MWI: medical waste incineration factory; EI: electronic factory; PILI: pharmaceutical factory in large infusion; OMC: oral medication class factory; IC: inorganic chemical factory; OC: organic chemical factory; PM: paper mills factory; MF: mechanical factory) 


\subsection{Measurement of HRGC/HRMS analysis}

$17 \mathrm{PCDD} / \mathrm{Fs}$ congeners were analyzed by high resolution gas chromatography (HRGC) (Thermo Trace GC) and high resolution mass spectrometry (HRMS) (Thermo DFS) according to the Chinese national standard (HJ77.4) at Jiangsu Levei Testing Company Limited, China. The procedure is described in related study (Colombo et al., 2009). Briefly, the dioxin congeners were analyzed by HRGC-HRMS using a fused silica capillary column DB-5 MS(60 m×0.25 $\mathrm{mm} \times 0.25 \mu \mathrm{m}, \mathrm{J} \& \mathrm{~W}$ ). The determined procedure was also described in the related literature (Meng et al., 2016). The column oven temperature was programmed at $140^{\circ} \mathrm{C}$ for $1 \mathrm{~min}$, increase to $200^{\circ} \mathrm{C}$ at a rate of $20^{\circ} \mathrm{C} \mathrm{min}$, then increase to $220^{\circ} \mathrm{C}$ at a rate of $5^{\circ} \mathrm{C} / \mathrm{min}$, then increased to $235^{\circ} \mathrm{C}$ at a rate of $5^{\circ} \mathrm{C} \mathrm{min}$, finally increased to $310^{\circ} \mathrm{C}$ at a rate of $5^{\circ} \mathrm{C} \mathrm{min}$, and SIM mode was used at resolution of $>10000$.

\subsection{QA/QC}

For each batch of 10 real samples, a quality control procedure was processed, including method blank, field blank and matrix spiked sample; each sample was determined for 7 times, and the relative standard deviation were lower than $2.4 \%$. Limit of detections (LODs) varied from 0.019 to $0.83 \mathrm{pg} / \mathrm{Nm}^{3}$ for HRGC/HRMS. In most cases, the concentrations of PCDD/Fs in blanks were below the LODs. Recovery efficiencies of 17 2,3,7,8-substituted ${ }^{13} \mathrm{C}$-labeled PCDD/Fs were ranged from $78 \%$ to $124 \%$. All the reported results were corrected with the values of blanks and recoveries.

\subsection{Health risk assessment}

Ambient air concentrations of PCDD/Fs in factories were used to calculate human exposure. Lifetime average daily doses (LADDs) and their resultant excess cancer risks (ECRs) for workers in this factories, calculation of LADD and ECR were based on equation(1) (Shih et al., 2008):

$$
\mathrm{LADD}=\left[\mathrm{V}_{\mathrm{R}} \mathrm{C} \mathrm{f}_{\mathrm{r}}\left(\mathrm{T}_{\mathrm{f}} / 24\right)\left(\mathrm{D}_{\mathrm{f}} / 365\right)\left(\mathrm{Y}_{\mathrm{f}} / 70\right)\right] / \mathrm{BW}, \mathrm{ECR}=\mathrm{LADD} \times \mathrm{ql}
$$

The symbols in equation (1) have been explained in detail in scientific literature (Shih et al., 2008). In briefly, LADD: lifetime average daily dose via inhalatory exposure ( $\mathrm{pg}$ I-TEQ $\mathrm{d}^{-1} \mathrm{~kg}^{-1}$ ); $\mathrm{V}_{\mathrm{r}}$ : ventilation rate for adults $\left(20 \mathrm{Nm}^{3} \mathrm{~d}^{-1}\right.$ ); C: the mean total I-TEQ exposure level (pg I-TEQ 
$\left.\mathrm{Nm}^{-3}\right) ; \mathrm{f}_{\mathrm{r}}$ : the alveolar fraction retained in the lung $(0.75) ; \mathrm{T}_{\mathrm{f}}:$ time spent at the impact site per day ( $8 \mathrm{~h}$ for workers); $\mathrm{D}_{\mathrm{f}}$ : days spent at the impact site per year (260 days for workers); $\mathrm{Y}_{\mathrm{f}}$ : years spent at the impact site in their lifetime (30 years for workers); BW: body weight for adults (70 kg); ql: unit cancer risk of $1 \times 10^{-3}\left(\mathrm{pg}\right.$ I-TEQ $\left.\mathrm{d}^{-1} \mathrm{~kg}^{-1}\right)$.

\subsection{Statistics}

PCDD/F concentrations were calculated as toxic equivalents (TEQs) using toxic equivalent factors (TEFs) (Kutz et al., 1990). The statistical analysis of the data was executed by means of the SPSS 20.0 software package. Significant differences in spatial groups were analyzed by ANOVA depending on the data distribution. Significant difference was set at $\mathrm{p}<0.05$.

\section{Result and discussion}

\subsection{PCDD/Fs concentration in ambient air}

Different congeners and sampling points were considered for different sampling rate based on related literature (Vilavert et al., 2014), and air samples were collected by means of passive samplers, these campaigns of the sampling rates ranged from 0.70 to $2.98 \mathrm{~m}^{3} / \mathrm{day}$. The results of the study are shown in Fig. 2, the TEQ of PCDD/Fs from different types of factories ranged from 0.0814 to $1.224 \mathrm{pg} \mathrm{I-TEQ} / \mathrm{m}^{3}$, and the mean values of TEQ in ambient air of factories were in the decreasing order of MWI $>$ MSWI $>$ PILI $>$ MF $>$ OC $>$ SST $>$ HSWI $>$ OMC $>$ PM $>$ EF $>$ IC.

As we know, MWI and MSWI were most important source of PCDD/Fs, due to that thermal processes and production process in those factories might produce numerous PCDD/Fs (Chen et al., 2014). Then TEQ in ambient air from MWI and MSWI was higher than other types factories. The highest values of TEQ were located in MWI station. Zhang et al (2016) noted that chlorophenols have higher formation rates of PCDD/Fs than chlorobenzenes, due to the reaction of the phenolichydroxyl, and the content of chloride in medicine were higher than in other materials of another ten types factories. In addition, the TEQ in PM, IC and EF were lower than other types factories. It it could be explained by that PCDD/Fs are unintentional by-products of combustion processes. However, the production process of PM, IC and EF has not combustion processes. In addition, the level concentrations of $\mathrm{PCDD} / \mathrm{Fs}$ were in the decreasing order of $\mathrm{EF}>$ $\mathrm{OC}>\mathrm{MSWI}>\mathrm{MWI}>\mathrm{HSWI}>\mathrm{OMC}>\mathrm{SST}>\mathrm{MF}>\mathrm{PILI}>\mathrm{PM}>\mathrm{IC}$. This is because that the 
toxic mainly from 2,3,7,8-TCDD, and different congeners have different TEFs between concentrations and toxic equivalent.

Significant difference between any two types of factories which were not observed based on toxic equivalency $(P=0.147-0.974)$, especially based on concentration $(\mathrm{P}>0.05)$. In order to further investigate ambient air quality, the TEQ of PCDD/Fs in ambient air from 11 factories were compared with the Japanese limit standard $\left(0.6 \mathrm{pg} \mathrm{I}-\mathrm{TEQ} / \mathrm{m}^{3}\right)$. The result indicted that average value of TEQs in all samples from these studies were lower than the limit value.

\section{Fig. 2 The content of PCDD/Fs in different types of factories}

The ambient air levels of PCDD/Fs in different types were also sampled and determined under the same meteorological conditions (Mari et al., 2008). According to previous reports (Die et al., 2015; Wang et al., 2016), the TEQ of PCDD/Fs were different at different sampling sites , and the concentrations at all of the industrial sites were higher than of the reference site. In order to more accurate analysis and assessment, in the study, the downwind points were chosen as the best sampling points in the factories giving more real result. In addition, the relevant report (Oh et al., 2006) pointed out the large variation of PCDD/Fs concentrations measured from ambient air in different MSWI. In this research, the values of PCDD/Fs on the windward side of MSWI ranged from 0.221 to $1.161 \mathrm{pg} \mathrm{I}-\mathrm{TEQ} / \mathrm{Nm}^{3}$ with an average value of $0.66 \mathrm{pg} \mathrm{I}-\mathrm{TEQ} / \mathrm{Nm}^{3}$, and the value of TEQ of PCDD/Fs on the downside of MSWI ranged from 0.119 to $0.768 \mathrm{pg}$ I-TEQ/ $\mathrm{Nm}^{3}$ with an average value of $0.373 \mathrm{pg}$ I-TEQ/ $/ \mathrm{Nm}^{3}$. The study was consistent with Oh et al (2015).

3.2 The profile of PCDD/Fs congeners in ambient air

In general, there are two kinds of expression, including concentration and toxic equivalent of PCDD/Fs (Vallejo et al., 2015b), the later was chosen as the expression to analyze 17 congeners of PCDD/Fs in ambient air (Xu et al., 2013).

\section{Fig. 3. The content of PCDD, PCDF and the ratio of PCDD/PCDF}

From Fig. 3, the average ratio of PCDD/PCDF in 11 different types factories ranged from 0.12 to 1.59. For OC, the ratios values was the highest (1.59), and the ratios of PCDD/PCDF in IC and OC were more than 1.0, the others were less than 1.0. Some researches indicated that 
$\mathrm{PCDD} / \mathrm{PCDF}$ ratios of most incinerators were less than 1 and homologue profiles were consistent (Xu et al., 2013). In present study, the ratios of PCDD/PCDF in HWI and MSWI were 0.18 and 0.51, respectively, which was consistent with the existing studies. Baker and Hites (2000) summarized this profile (Fig. 3a) from 12 types of combustion sources based on the "Database of sources of environmental releases of dioxin-like compounds in the United States" (U.S. EPA, 1998b) and the profile was characterized by PCDD/PCDF ratio < 1. In our research, the ratios of $\mathrm{PCDD} / \mathrm{PCDF}$ were less than 1.0 except in I/Fs in different types factories were in the range of 4.0\%-20.9\%, and the decreasing order was of MWI $>$ OC $>$ SST $>$ IC $>$ OMC $>$ PM $>$ PILI > $\mathrm{HSWI}>\mathrm{EF}>\mathrm{MF}>\mathrm{MSWI}$. The average ratio of PCDFs in PCDD/Fs for different types factories ranges from $11.57 \%$ to $33.31 \%$, and the decreasing order was of $\mathrm{IC}<\mathrm{OC}<\mathrm{PM}<\mathrm{EF}<\mathrm{SST}<$ OMC $<$ HSWI $<$ PILI $<$ MWI $<$ MF $<$ MSWI.

\section{Fig. 4. The profile of PCDD/Fs congeners in different types factories}

According to the PCDD/Fs congener profiles in Fig.3, the highest values of TEQ of PCDD/Fs congeners was 2,3,7,8- $\mathrm{T}_{4} \mathrm{CDD}$ in IC of eleven types factories. The values of 2,3,6,7,8- $\mathrm{H}_{6} \mathrm{CDD}$, 2,3,7,8,9- $\mathrm{H}_{6} \mathrm{CDD}, \mathrm{O}_{8} \mathrm{CDD}, 1,2,3,6,7,8-\mathrm{H}_{6} \mathrm{CDF}$ and $1,2,3,7,8,9-\mathrm{H}_{6} \mathrm{CDF}$ were the highest in MWI type of all. 1,2,3,7,8- $\mathrm{P}_{5} \mathrm{CDF}, 1,2,3,4,7,8-\mathrm{H}_{6} \mathrm{CDF}, 1,2,3,4,6,7,8-\mathrm{H}_{7} \mathrm{CDF}$ and $\mathrm{O}_{8} \mathrm{CDF}$ in MSWI type have the max values. In addition, the values of $1,2,3,4,7,8-\mathrm{H}_{6} \mathrm{CDF}$ in PILI and MSWI were equal, and it was much higher than other types. The result showed that the max value PCDD/Fs congeners were distributed in different factories types. What is more, the result also showed that the impact of combustion process on the PCDD/F profiles in ambient air (Bi et al., 2015) and its distribution were mainly depend on the types and sites of ambient air.

To further analyze 17 congeners in those types, correlation coefficient of these congeners was

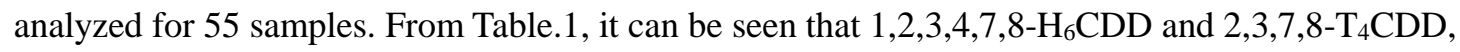
1,2,3,7,8- $\mathrm{P}_{5} \mathrm{CDD}, 1,2,3,6,7,8-\mathrm{H}_{6} \mathrm{CDD}$ exhibited high positive correlation, and the correlation coefficient between $1,2,3,6,7,8-\mathrm{H}_{6} \mathrm{CDD}$ and $1,2,3,7,8,9-\mathrm{H}_{6} \mathrm{CDD}$ was 0.857 . However, all of result from Fig. 4 and Table. 1 proved that seventeen congeners in those different types factories had similar congener profiles, which matched well with the reported results (2014) (Zhang et al., 2014). 


\section{Table 1 Correlation coefficient matrix.}

\subsection{Health risk assessment}

In order to calculate total I-TEQ exposure, ECRs of workers in those factories by the equation in Part 2.4 was estimated. The results of ECR of PCDD/Fs in 11 kinds of factories were listed in Table2. The values of ECRs ranged from $1.78 \times 10^{-6}$ to $2.67 \times 10^{-5}$. The value of ECR in MWI type was much higher than other type factories. However, the lowest value was located in IC.

Under most regulatory programs, a ECR value below $10^{-6}$ indicates negligible cancer risk, whereas a value between $10^{-6}$ and $10^{-4}$ suggests potential cancer risk, and a value above $10^{-4}$ is an indication of high-potential risk ( $\mathrm{Li}$ et al., 2016; Kamal et al., 2014). It indicated that workers might be harmed by PCDD/Fs in ambient air in those factories, and it also suggested that proper personal protection equipment should be used in the factories to effectively reduce workers' exposure. According to numbers of scientific reports, which was used to control PCDD/Fs formation and emission in recent years (Rovira et al., 2014; Rovira et al., 2015), different methods based on different formation mechanism. Atkinson et al (2015) showed that PCDD/Fs were generated via denovo synthesis during waste combustion, and it is beneficial to develop carbon-based sorbents to destroy PCDD/Fs. Vallejo et al (2015a) also proposed that PCDD/Fs could be formed during remediation of chlorinated phenols via Fenton oxidation, and it could be applied to different concentrations of iron dose to inhibit formation of PCDD/Fs.

\section{Table 2 The values of ECR of PCDD/Fs in ambient air from 11 kinds of factories}

Therefore, reduce residence time in factories, proper personal protection equipment and change incineration styles to lower health risk index, and it is most important to transform combustion process and production process by the actual process of MSWI, MWI, HSWI, SST, MF, OC, IC, OMC, EF, PM and PILI.

\section{Conclusions}

The comparison of PCDD/F levels in ambient air of different factories in an southern 
area ,China, including MSWI, MWI, HSWI, SST, MF, OC, IC, OMC, EF, PM and PILI were studied. The PCDD/Fs levels in the study were ranged from $0.236 \pm 0.198$ to $0.48 \pm 0.442 \mathrm{pg}$ $\mathrm{I}-\mathrm{TEQ} / \mathrm{Nm}^{3}$ in 11 kinds of factories. The ratios of PCDD/PCDF in all type factories were less than 1.0 except OC and IC. Besides, by comparing 17 congeners in 11 kinds of factories, the result showed that seventeen congeners in those different types factories have similar congener profiles. The health risk of workers impacted by PCDD/Fs in ambient air of different types of factories were higher than $10^{-6}$, and it suggested that potential cancer risk occurred.

\section{Acknowledgments}

The samples were test by Jiangsu Levei Testing Company Limited of China. This research was supported by National Science Foundation of China (81472920 and 81402626),and the Priority A cademic Program Development of Jiangsu Higher Education Institutions, China and Jiangsu Provi nce Postdoctoral Science Foundation Grant (2015M571811, 1402175C).

\section{References}

Atkinson, J.D., Hung, P.C., Zhang, Z., Chang, M.B., Yan, Z., Rood, M.J., 2015. Adsorption and destruction of PCDD/Fs using surface-functionalized activated carbons. Chemosphere. 118, 136-142.

Baker, J.I., Hites, R.A., 2000. Is combustion the major source of polychlorinated dibenzo-p-dioxins and dibenzofurans to the environment? a mass balance investigation. Environ. Sci. Technol. 34, 2879-2886.

Bi, W.-z., Zhao, R.-d., Chen, T.-j., Wu, J.-l., Wu, J.-h., 2015. Study on the formation of PCDD/Fs in PVC chemical looping combustion. J.Fuel ChemTechnol.43, 884-889.

Chen, T., Zhan, M.X., Lin, X.Q., Li, X.D., Lu, S.Y., Yan, J.H., Buekens, A., Cen, K.F., 2014. Inhibition of the de novo synthesis of PCDD/Fs on model fly ash by sludge drying gases. Chemosphere .114, 226-232.

Chi, K.H., Lin, C.-Y., Wang, S.-H., Lin, N.-H., Sheu, G.-R., Lee, C.-T., 2013. Evaluation of the distributions of ambient $\mathrm{PCDD} / \mathrm{Fs}$ at remote locations in and around Taiwan. Atmos. Environ.78, 203-210.

Colombo, A., Benfenati, E., Mariani, G., Lodi, M., Marras, R., Rotella, G., Senese, V., Fattore, E., Fanelli, R., 2009. PCDD/Fs in ambient air in north-east Italy: the role of a MSWI inside an industrial area. Chemosphere .77, 1224-1229. 
Die, Q., Nie, Z., Liu, F., Tian, Y., Fang, Y., Gao, H., Tian, S., He, J., Huang, Q., 2015. Seasonal variations in atmospheric concentrations and gas-particle partitioning of PCDD/Fs and dioxin-like PCBs around industrial sites in Shanghai, China. Atmos. Environ.119, 220-227.

Fu, J.Y., Li, X.D., Chen, T., Lin, X.Q., Buekens, A., Lu, S.Y., Yan, J.H., Cen, K.F., 2015. PCDD/Fs' suppression by sulfur-amine/ammonium compounds. Chemosphere.123, 9-16.

Kamal A, Malik RN, Martellini T, Cincinelli A, 2014. Cancer risk evaluation of brick kiln workers exposed to dust bound PAHs in Punjab province (Pakistan). Sci. Total Environ. 493: $562-570$.

Kutz, F.W., Barnes, D.G., Bottimore, D.P., Greim, H., 1990. The international toxicity equivalency factor (I-TEF) method of risk assessment for complex mixtures of dioxins and related compounds. Chemosphere 20, $751-757$.

Li, J., Dong, H., Xu, X., Han, B., Li, X., Zhu, C.,Zhang, D., 2016. Prediction of the bioaccumulation of PAHs in surface sediments of Bohai Sea, China and quantitative assessment of the related toxicity and health risk to humans. Mar. Pollut. Bullet.104(1), 92-100.

Liu, G., Jiang, X., Wang, M., Dong, S., Zheng, M., 2015. Comparison of PCDD/F levels and profiles in fly ash samples from multiple industrial thermal sources. Chemosphere. 133, 68-74.

Mari, M., Nadal, M., Schuhmacher, M., Domingo, J.L., 2008. Monitoring PCDD/Fs, PCBs and metals in the ambient air of an industrial area of Catalonia, Spain. Chemosphere .73, 990-998.

Meng, B., Ma, W.-L., Liu, L.-Y., Zhu, N.-Z., Song, W.-W., Lo, C.Y., Li, J., Kannan, K., Li, Y.-F., 2016. PCDD/Fs in soil and air and their possible sources in the vicinity of municipal solid waste incinerators in northeastern China. Atmos. Pollu. Res.7, 355-362.

Oh, J.E., Choi, S.D., Lee, S.J., Chang, Y.S., 2006. Influence of a municipal solid waste incinerator on ambient air and soil PCDD/Fs levels. Chemosphere.64, 579-587.

Ortuno, N., Lundstedt, S., Lundin, L., 2015. Emissions of PBDD/Fs, PCDD/Fs and PBDEs from flame-retarded high-impact polystyrene under thermal stress. Chemosphere.123, 64-70.

Rovira, J., Nadal, M., Schuhmacher, M., Domingo, J.L., 2014. Environmental levels of PCDD/Fs and metals around a cement plant in Catalonia, Spain, before and after alternative fuel implementation. Assessment of human health risks. Sci.Toal Environ.485-486, 121-129.

Rovira, J., Vilavert, L., Nadal, M., Schuhmacher, M., Domingo, J.L., 2015. Temporal trends in the levels of metals, PCDD/Fs and PCBs in the vicinity of a municipal solid waste incinerator. Preliminary assessment of human health risks. Waste Manage.43, 168-175. 
Shi, D.Z., Wu, W.X., Lu, S.Y., Chen, T., Huang, H.L., Chen, Y.X., Yan, J.H., 2008. Effect of MSW source-classified collection on the emission of PCDDs/Fs and heavy metals from incineration in China. J.Hazard.Mater.153, 685-694.

Shih, T. S., Lee, W. J., Shih, M., Chen, Y. C., Huang, S. L., Wang, L. C., Tsai, P. J., 2008. Exposure and health-risk assessment of polychlorinated dibenzo-p-dioxins and dibenzofurans (PCDD/Fs) for sinter plant workers. Environ. Int.34(1), 102-107.

Squadrone, S., Prearo, M., Nespoli, R., Scanzio, T., Abete, M.C., 2016. PCDD/Fs, DL-PCBs and NDL-PCBs in European catfish from a northern Italian lake: the contribution of an alien species to human exposure. Ecotox. Environ. Safe.125, 170-175.

Vallejo, M., Fernandez-Castro, P., San Roman, M.F., Ortiz, I., 2015a. Assessment of PCDD/Fs formation in the Fenton oxidation of 2-chlorophenol: Influence of the iron dose applied. Chemosphere. 137, 135-141.

Vallejo, M., Fresnedo San Roman, M., Ortiz, I., Irabien, A., 2015b. Overview of the PCDD/Fs degradation potential and formation risk in the application of advanced oxidation processes (AOPs) to wastewater treatment. Chemosphere. 118, 44-56.

Vilavert, L., Nadal, M., Schuhmacher, M., Domingo, J.L., 2014. Seasonal surveillance of airborne PCDD/Fs, PCBs and PCNs using passive samplers to assess human health risks. Sci.Total Environ. 466-467, 733-740.

Wang, P., Shang, H., Li, H., Wang, Y., Li, Y., Zhang, H., Zhang, Q., Liang, Y., Jiang, G., 2016. PBDEs, PCBs and PCDD/Fs in the sediments from seven major river basins in China: Occurrence, congener profile and spatial tendency. Chemosphere .144, 13-20.

Wegiel, M., Chrzaszcz, R., Maslanka, A., Grochowalski, A., 2014. Study on the impact of industrial flue gases on the PCDD/Fs congener profile in ambient air. Chemosphere .114, 76-83.

Xu, P., Tao, B., Li, N., Qi, L., Ren, Y., Zhou, Z., Zhang, L., Liu, A., Huang, Y., 2013. Levels, profiles and source identification of $\mathrm{PCDD} / \mathrm{Fs}$ in farmland soils of Guiyu, China. Chemosphere .91, 824-831.

Zhang, M., Buekens, A., Li, X., 2016. Brominated flame retardants and the formation of dioxins and furans in fires and combustion. J.Hazard.Mater.. 304, 26-39.

Zhang, M., Zhang, S., Zhang, Z., Xu, Z., Feng, G., Ren, M., 2014. Influence of a municipal solid waste incinerator on ambient air PCDD/F levels: a comparison of running and non-running periods.Sci.Total Environ. 491-492, 34-41. 


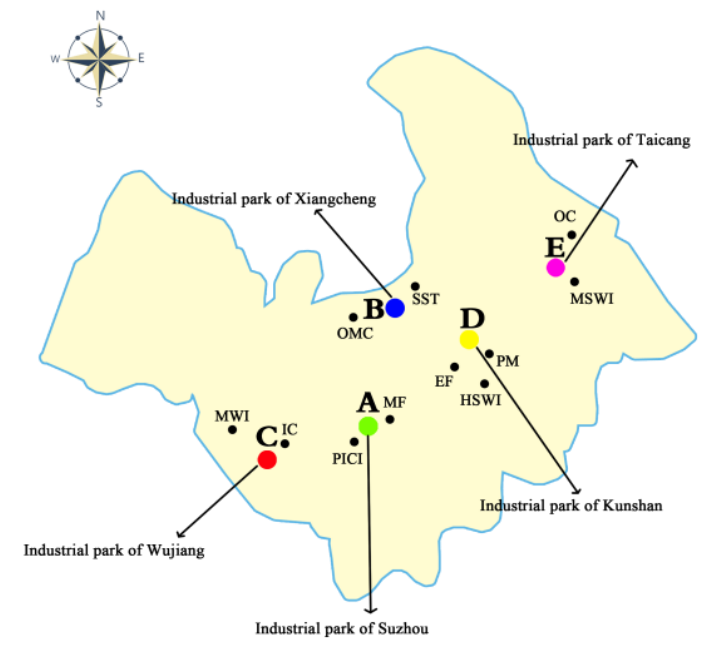

Fig.1 Map of the studied area in this study (MSWI: municipal solid waste incineration factory; HSWI: hazardous solid waste incineration factory;SSI: sewage sludge treatment factory; MWI: medical waste incineration factory; EI: electronic factory; PILI: pharmaceutical factory in large infusion; OMC: oral medication class factory; IC: inorganic chemical factory; OC: organic chemical factory; PM: paper mills factory; MF: mechanical factory) 

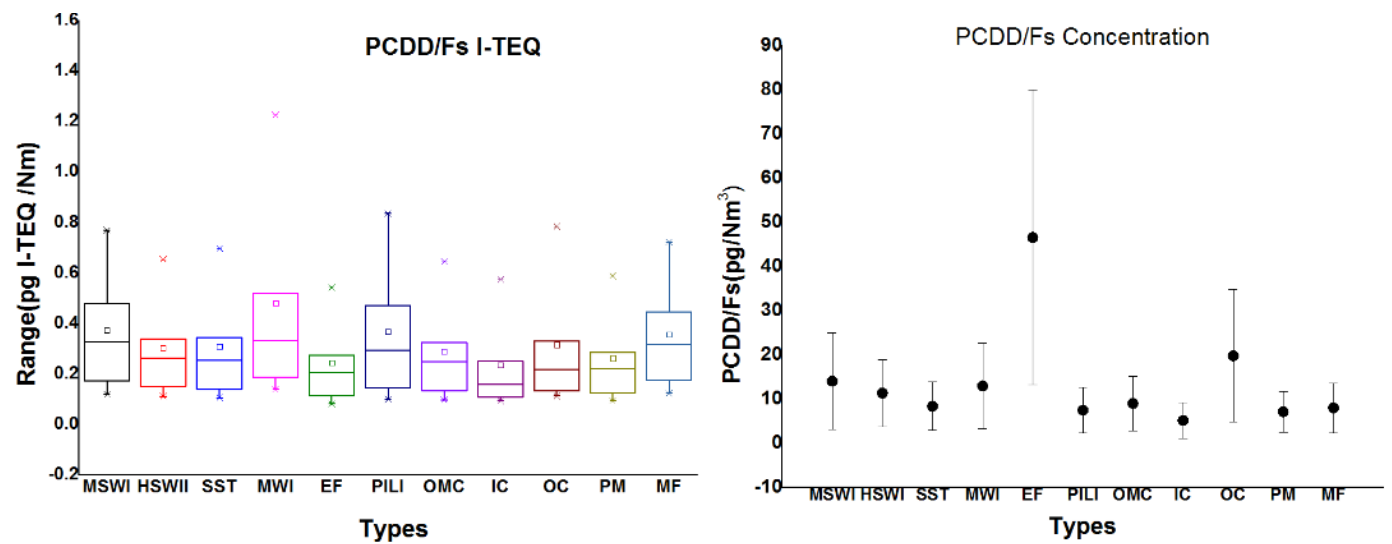

Fig. 2 The content of PCDD/Fs in different types of factories. 


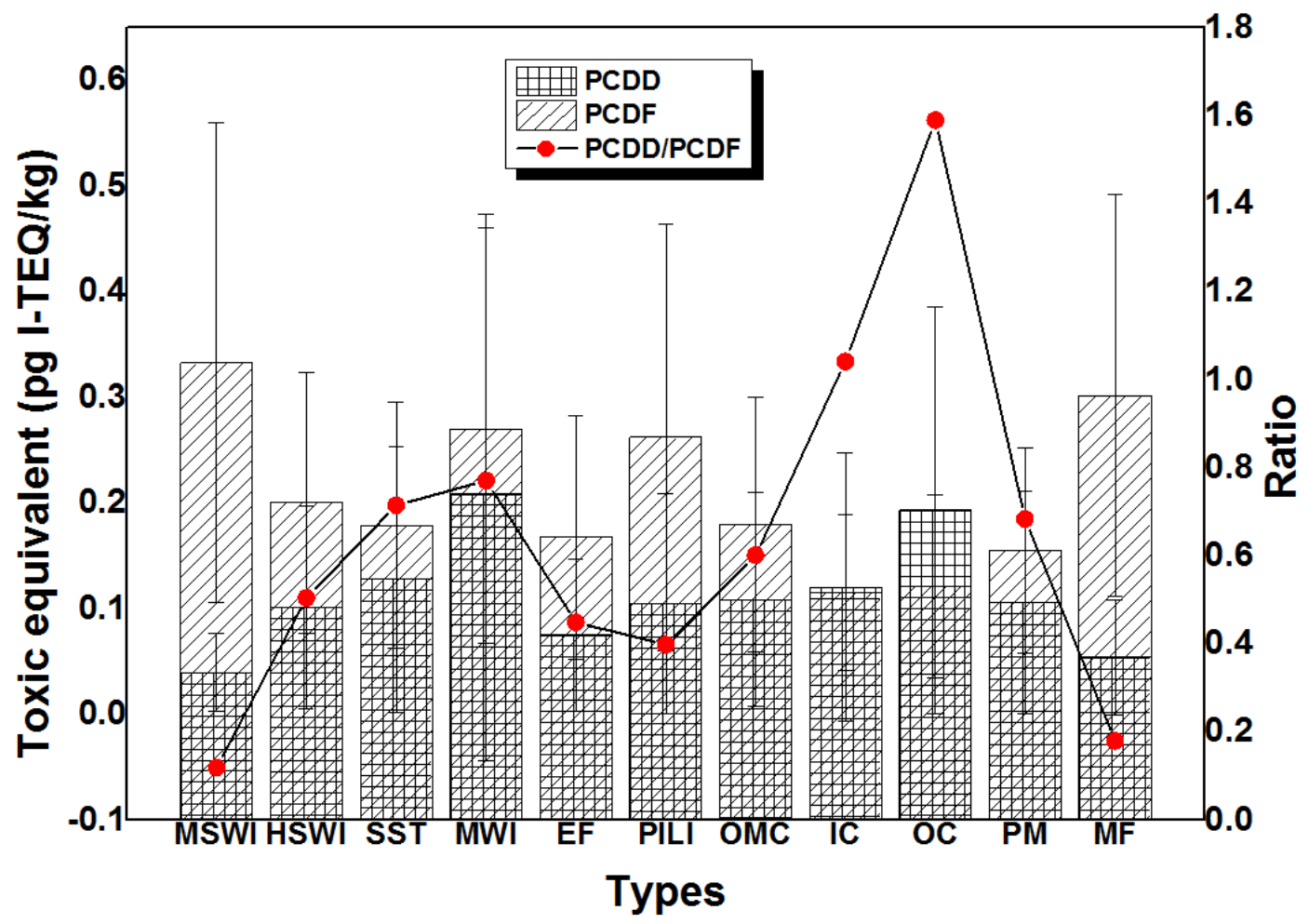

Fig. 3. The content of PCDD, PCDF and the ratio of PCDD/PCDF. 


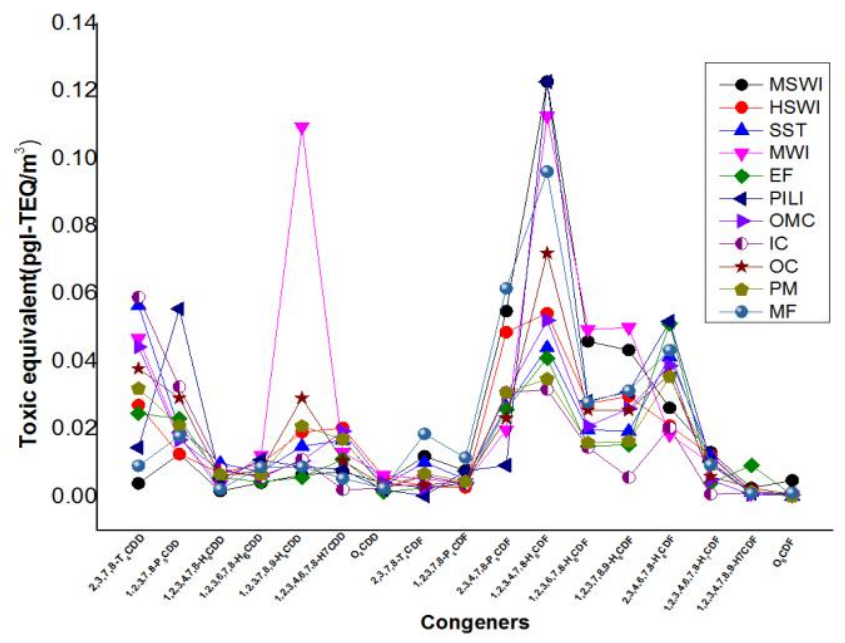

Fig. 4. The profile of PCDD/Fs congeners in different factories types. 


\section{Table 1 Correlation coefficient matrix}

$2,3,7,8-1,2,3,7,81,2,3,4,7,1,2,3,6,7,1,2,3,7,8,1,2,3,4,6,7$ O8 $2,3,7,8-1,2,3,7,82,3,4,7,8 \quad 1,2,3,4,7,1,2,3,6,7,1,2,3,7,8,2,3,4,6,7,1,2,3,4,6,7$

T4CDD -P5CDD 8-H6CD 8-H6CD 9-H6CD ,8-H7CDD CD T4CDF -P5CDF -P5CDF 8-H6CD 8-H6CD 9-H6CD 8-H6CD ,8-H7CDF

\begin{tabular}{|c|c|c|c|c|c|c|c|c|c|c|c|c|c|c|c|}
\hline & & & $\mathrm{D}$ & $\mathrm{D}$ & $\mathrm{D}$ & & $\mathrm{D}$ & & & & F & $\mathrm{F}$ & F & F & \\
\hline $2,3,7,8-\mathrm{T} 4$ & 1 & 0.656 & 0.756 & 0.554 & 0.412 & 0.267 & 0.7 & -0.034 & 0.339 & -0.13 & 0.146 & 0.41 & -0.005 & 0.383 & -0.178 \\
\hline CDD & & & & & & & 66 & & & & & & & & \\
\hline $1,2,3,7,8-\mathrm{P}$ & 0.656 & 1 & 0.718 & 0.751 & 0.295 & 0.099 & 0.4 & -0.099 & 0.681 & -0.12 & 0.471 & 0.587 & 0.121 & 0.678 & -0.048 \\
\hline $5 \mathrm{CDD}$ & & & & & & & 39 & & & & & & & & \\
\hline $1,2,3,4,7,8$ & 0.756 & 0.718 & 1 & 0.724 & 0.332 & 0.393 & 0.3 & -0.077 & 0.522 & 0.061 & 0.258 & 0.558 & 0.055 & 0.633 & -0.003 \\
\hline -H6CDD & & & & & & & 81 & & & & & & & & \\
\hline $1,2,3,6,7,8$ & 0.554 & 0.751 & 0.724 & 1 & 0.686 & 0.348 & 0.4 & 0.041 & 0.759 & 0.16 & 0.642 & 0.857 & 0.45 & 0.64 & 0.226 \\
\hline$-\mathrm{H} 6 \mathrm{CDD}$ & & & & & & & 37 & & & & & & & & \\
\hline $1,2,3,7,8,9$ & 0.412 & 0.295 & 0.332 & 0.686 & 1 & 0.225 & 0.3 & -0.034 & 0.304 & -0.012 & 0.389 & 0.695 & 0.404 & 0.172 & 0.085 \\
\hline -H6CDD & & & & & & & 42 & & & & & & & & \\
\hline $1,2,3,4,6,7$ & 0.267 & 0.099 & 0.393 & 0.348 & 0.225 & 1 & 0.4 & 0.026 & 0.084 & 0.07 & 0.176 & 0.244 & 0.506 & 0.489 & 0.466 \\
\hline ,8-H7CDD & & & & & & & 02 & & & & & & & & \\
\hline O8CDD & 0.766 & 0.439 & 0.381 & 0.437 & 0.342 & 0.402 & 1 & 0.105 & 0.265 & -0.034 & 0.263 & 0.381 & 0.284 & 0.285 & 0.018 \\
\hline $2,3,7,8-\mathrm{T} 4$ & -0.034 & -0.099 & -0.077 & 0.041 & -0.034 & 0.026 & 0.1 & 1 & 0.301 & 0.567 & 0.378 & 0.072 & 0.333 & 0.212 & 0.5 \\
\hline $\mathrm{CDF}$ & & & & & & & 05 & & & & & & & & \\
\hline $1,2,3,7,8-\mathrm{P}$ & 0.339 & 0.681 & 0.522 & 0.759 & 0.304 & 0.084 & 0.2 & 0.301 & 1 & 0.422 & 0.661 & 0.794 & 0.365 & 0.705 & 0.185 \\
\hline $5 \mathrm{CDF}$ & & & & & & & 65 & & & & & & & & \\
\hline $2,3,4,7,8-\mathrm{P}$ & -0.13 & -0.12 & 0.061 & 0.16 & -0.012 & 0.07 & -0.0 & 0.567 & 0.422 & 1 & 0.245 & 0.319 & 0.302 & 0.149 & 0.31 \\
\hline
\end{tabular}




\begin{tabular}{|c|c|c|c|c|c|c|c|c|c|c|c|c|c|c|c|}
\hline $1,2,3,4,7,8$ & 0.146 & 0.471 & 0.258 & 0.642 & 0.389 & 0.176 & 0.2 & 0.378 & 0.661 & 0.245 & 1 & 0.65 & 0.647 & 0.546 & 0.613 \\
\hline -H6CDF & & & & & & & 63 & & & & & & & & \\
\hline $1,2,3,6,7,8$ & 0.41 & 0.587 & 0.558 & 0.857 & 0.695 & 0.244 & 0.3 & 0.072 & 0.794 & 0.319 & 0.65 & 1 & 0.509 & 0.538 & 0.17 \\
\hline -H6CDF & & & & & & & 81 & & & & & & & & \\
\hline $1,2,3,7,8,9$ & -0.005 & 0.121 & 0.055 & 0.45 & 0.404 & 0.506 & 0.2 & 0.333 & 0.365 & 0.302 & 0.647 & 0.509 & 1 & 0.419 & 0.67 \\
\hline -H6CDF & & & & & & & 84 & & & & & & & & \\
\hline $2,3,4,6,7,8$ & 0.383 & 0.678 & 0.633 & 0.64 & 0.172 & 0.489 & 0.2 & 0.212 & 0.705 & 0.149 & 0.546 & 0.538 & 0.419 & 1 & 0.303 \\
\hline -H6CDF & & & & & & & 85 & & & & & & & & \\
\hline $1,2,3,4,6,7$ & -0.178 & -0.048 & -0.003 & 0.226 & 0.085 & 0.466 & 0.0 & 0.5 & 0.185 & 0.31 & 0.613 & 0.17 & 0.67 & 0.303 & 1 \\
\hline ,8-H7CDF & & & & & & & 18 & & & & & & & & \\
\hline $1,2,3,4,7,8$ & 0.642 & 0.507 & 0.383 & 0.236 & 0.082 & 0.096 & 0.6 & -0.061 & 0.258 & -0.081 & 0.092 & 0.24 & -0.064 & 0.4 & -0.215 \\
\hline ,9-H7CDF & & & & & & & 09 & & & & & & & & \\
\hline O8CDF & 0.093 & 0.25 & 0.098 & 0.21 & 0.06 & -0.091 & 0.2 & 0.255 & 0.576 & 0.445 & 0.5 & 0.606 & 0.33 & 0.238 & 0.147 \\
\hline & & & & & & & 27 & & & & & & & & \\
\hline
\end{tabular}


Table 2 The values of ECR of PCDD/Fs in ambient air from 11 kinds of factories

\begin{tabular}{|c|c|c|c|c|c|c|c|c|c|c|c|c|}
\hline \multicolumn{13}{|c|}{ Factory types } \\
\hline- & $\mathrm{M}$ & $\mathrm{IF}$ & PI & & $\mathrm{O}$ & C & I & $\mathrm{C}$ & ON & MC & PI & LI \\
\hline - & Rang & Average & Rang & Average & Rang & Average & Rang & Average & Rang & Average & Rang & Average \\
\hline \multirow{3}{*}{ ECR } & $2.69 \times 10^{-6}$ & & $2.04 \times 10^{-6}$ & & $2.45 \times 10^{-6}$ & & $1.69 \times 10^{-6}$ & & $2.11 \times 10^{-6}$ & & $2.15 \times 10^{-6}$ & \\
\hline & & $7.77 \times 10^{-5}$ & & $5.71 \times 10^{-6}$ & & $6.88 \times 10^{-6}$ & & $7.68 \times 10^{-6}$ & & $6.31 \times 10^{-5}$ & & $8.02 \times 10^{-6}$ \\
\hline & $\sim 1.57 \times 10^{-5}$ & & $\sim 1.28 \times 10^{-5}$ & & $\sim 1.71 \times 10^{-5}$ & & $\sim 1.15 \times 10^{-5}$ & & $\sim 1.40 \times 10^{-5}$ & & $\sim 1.82 \times 10^{-5}$ & \\
\hline- & \multicolumn{2}{|c|}{$\mathrm{EF}$} & \multicolumn{2}{|c|}{ MWI } & \multicolumn{2}{|c|}{ SST } & \multicolumn{2}{|c|}{ HSWI } & \multicolumn{2}{|c|}{ MSWI } & \multicolumn{2}{|c|}{--} \\
\hline- & Rang & Average & Rang & Average & Rang & Average & Rang & Average & Rang & Average & - & - \\
\hline \multirow{3}{*}{ ECR } & $1.78 \times 10^{-6}$ & & $3.02 \times 10^{-6}$ & & $2.31 \times 10^{-6}$ & & $2.41 \times 10^{-6}$ & & $2.59 \times 10^{-6}$ & & & \\
\hline & & $7.77 \times 10^{-6}$ & & $1.05 \times 10^{-5}$ & & $6.71 \times 10^{-5}$ & & $6.59 \times 10^{-5}$ & & $7.77 \times 10^{-6}$ & & \\
\hline & $\sim 1.18 \times 10^{-5}$ & & $\sim 2.67 \times 10^{-5}$ & & $\sim 1.52 \times 10^{-5}$ & & $\sim 1.42 \times 10^{-5}$ & & $\sim 1.12 \times 10^{-5}$ & & & \\
\hline
\end{tabular}

